\title{
Identifying spatial characteristics of transmissivity using simulated annealing and kriging methods
}

\author{
Yu-Pin Lin · Yih-Chi Tan · Shahrokh Rouhani
}

\begin{abstract}
Groundwater flow and transport modeling require proper and accurate hydrogeological properties. These hydrogeological data, including information on transmissivity or hydraulic conductivity, may contain significant uncertainty, displaying complex spatial variation. This study identified the spatial patterns and variations in transmissivity in the southeast of Yun-Lin County and the north of Chia-Yih County in Taiwan to reveal the spatial characteristics of hydrogeological formation for groundwater study. The spatial maps of transmissivity were estimated and simulated using ordinary kriging and simulated annealing methods. Correlation analysis revealed that realizations of simulations could fully display the characteristics of transmissivity within this study area. Correlation analysis also indicated that both estimation and simulation results displayed similar patterns. The spatial maps of the estimation and simulation of transmissivity indicated that simulated annealing could not only reproduce the statistics and spatial variation of the measured transmissivity, but could also identify the global spatial continuity patterns of transmissivity. The simulated maps of transmissivityalso fully illustrate the characteristics of the geological and aquifer characteristics of the study area.
\end{abstract}

Received: 12 December 2000 / Accepted: 29 May 2001 Published online: 14 July 2001

(C) Springer-Verlag 2001
Keywords Transmissivity - Simulated annealing · Ordinary kriging $\cdot$ Spatial characteristics

\section{Introduction}

All soil and geologic formations exhibit apparently random variations in their spatial hydrological properties (Freeze 1975). Transmissivity is a fundamental parameter of hydrogeological properties in characterizing aquifers for groundwater models. Proper modeling of preferential flow paths and of transport behavior requires the use of transmissivity fields which reproduce the spatial variability patterns observed in the field (Capilla and others 1998). These transmissivity fields sometimes contain significant uncertainties, including complex (unexplainable) variations in observed values of measurable attributes over the investigated area. These spatial and temporal variations can be extremely complicated. Thus, the reconstruction of the transmissivity field from the experimental hydraulic head data, an inverse problem, arises not only from the complexity of the diffusion equation linking the two variables, but also from considering the physical aspects of the site under study; such as the boundary conditions, the effective recharge, and the geology (Roth 1998).

In practical applications, the validity of the purely analytical techniques proposed to date is limited by certain assumptions which simplify their application, like linearizing the flow equation to obtain a solution (Roth 1998). Therefore, characterizing the spatial variabilities of transmissivity for groundwater models is important. Because of these variations in hydrogeological properties, numerous authors have used statistical procedures to model spatial structures of interesting geohydrologic and physicochemical properties. Examples of such works include Bakr and others (1978), Journel and Huijbregts (1978), Delhomme (1979), Smith and Freeze (1979), Chirlin and Dagan (1980), Smith (1981), Clifton and Neuman (1982), Anderson and Shapiro (1983), Hoeksema and Kitanidis (1985), Neuman and others (1987), Rubin (1990), Bjerg and others (1992), Fabbri (1996), Eggleston and others (1996), Christensen (1997), Di Federico and Neuman (1997), and Salandin and Fiorotto (1998). 
The kriging process yields weighted-average estimates which may fail to preserve the variability of the investigated process. Minimizing the variance in prediction error requires smoothing the actual variability (Journel and Huijbergts 1978). The estimated values based on kriging display a lower variation than the actual investigated values. To correct this shortcoming, geostatistical simulation can be performed. Simulation generates equally likely sets of values for a variable, which are consistent with available in-situ measurements. This frequently implies that the simulated values have the same mean and variogram as the original data, and may also coincide with the original data at measurement points. Simulation focuses mainly on reproducing the fluctuations in the observations, instead of producing the optimal prediction (Sterk and Stein 1997).

Geostatistical conditional simulation, such as by simulated annealing, attempts not only to generate a set of values with some specified mean and covariance, but also to reproduce observed data at several locations. Geologists use simulation to visualize fluctuations in major geologic patterns, investigate the fossil morphology, and map stratigraphical and structure surfaces (Christakos 1992). For instance, investigation measurements and simulated values can be used to analyze the spatial distribution of a particular variable. Varljen and Shafer (1991) established a conditional simulation to determine a cap by simulating transmissivity. Furthermore, Eggleston and others (1996) used geostatistical simulations and ordinary kriging to reproduce the hydraulic conductivity structure in the formation of natural $\log$, and made the structure sensitive to limited data. Later, Mowrer (1997) used sequential Gaussian simulation to map potential old-growth forest conditions across a 121 ha first-order subalpine watershed. Additionally, Sterk and Stein (1997) employed a simulated annealing method to create multiple realizations of windblown mass transport, thus overcoming the smoothing effect of kriging estimation. Furthermore, Kentwell and others (1999) used a sequential Gaussian fractal simulation to increase the prediction accuracy of the grade tonnage curve. Meanwhile, Wang and Zhang (1999) used a turning band method to reproduce multiple realizations for heavy metals. Also, Lin and Chang (2000a) used sequential Gaussian simulation to map the spatial pattern and identify polluted sites of soil heavy metals. Lin and others (2000) applied sequential Gaussian simulation to characterize spatial structure of transmissivity. Finally, Lin and Chang (2000b) applied sequential Gaussian simulation to characterize spatial structure of transmissivity.

This study uses conditional simulation techniques and ordinary kriging to produce the realizations and maps of transmissivity in a real case study. The descriptive statistics, spatial structure (experimental variogram), correlation and spatial patterns of estimated and simulated results are also discussed herein. Finally, the estimation and simulation results are mapped into GIS to compare with the spatial distribution of geological formation for characterizing and verifying the spatial distribution of estimated and simulated transmissivity in the study area.

\section{Materials and methods}

The selected study area covers $154.67 \mathrm{~km}^{2}$ and is on the east banks of the middle and upper streams of the Peikang River in the southeast part of Yun-Lin County and the north part of Gia-Yih County, Taiwan (Fig. 1). Figure 1 displays the branch streams of the Peikang River. The geological features of the study area from Dulliu Hill to the Peikang River include the Toukoshan Formation, Lichi Formation, terrace deposits and alluvium, as presented in Fig. 1. Part of the west bank of the Peikang River belongs to the alluvia fan of the Chuo-Shuei River. The fan has a typical alluvia fan stratum structure, with a thick gravel layer on the east side reducing gradually to the west and southwest, whereas the muddy and sandy stratum thickens. Tsao (1982) studied and reported the field data of the welldrilling lag and the aquifer of this study area. According to the reports of Tsao (1982) and Lin and others (2000), Tapei city has the deepest well bores in the county, with an average depth of $199.7 \mathrm{~m}$. Meanwhile, wells in Talin town rank second, with an average depth of $179.3 \mathrm{~m}$, and wells in Tounan and Kukeng towns are 176.5 and $106.5 \mathrm{~m}$, respectively (Tsao 1982; Lin and others 2000). The average thickness of the aquifer in the well-drilling log ranges from 30.6 to $52.8 \mathrm{~m}$. The depth of the aquifer in the alluvia fan part of the Chuo-Shuei River and the west bank of the Peikang River is $80 \mathrm{~m}$ at Huwei town and an average of $100 \mathrm{~m}$ at Tuku and Yuanchang towns (Lin and others 2000). Figure 2a presents the locations of sampling wells of transmissivity data measured by using the pumping test and provided by $\mathrm{Yu}$-Ling Irrigation Association. Figure $2 \mathrm{~b}$ illustrates the measured values of transmissivity ranged from 8.637 to $407.483 \mathrm{~m}^{2} / \mathrm{h}$ at the sampling points of this study area. Table 1 lists the basic descriptive statistics of the measured data. Meanwhile, Fig. 3a presents the histogram of the measured transmissivity. These results confirm that the measured transmissivity data display a skewed distribution and a significant spatial variation.

\section{Ordinary kriging}

Geostatistical techniques like kriging incorporate the spatial or temporal characteristics of actual data into statistical estimation. Geostatistics provide a variogram of data within a statistical framework, including spatial and temporal covariance functions. As expected, these variogram models are termed spatial or temporal structures, and are defined in terms of the correlation between any two points separated either spatially or temporally. Variograms provide a means of quantifying the commonly observed relationship whereby samples close together tend to have more similar values than samples farther apart. The variogram $\gamma(h)$ is defined as:

$\gamma(h)=(1 / 2) \operatorname{Var}[Z(x)-Z(x+h)]$

where $h$ denotes the lag distance separating pairs of points, Var represents the variance of the argument, $Z(x)$ is the value of the regionalized variable of interest at location $x$, and $Z(x+h)$ denotes the value at the location $x+h$. 


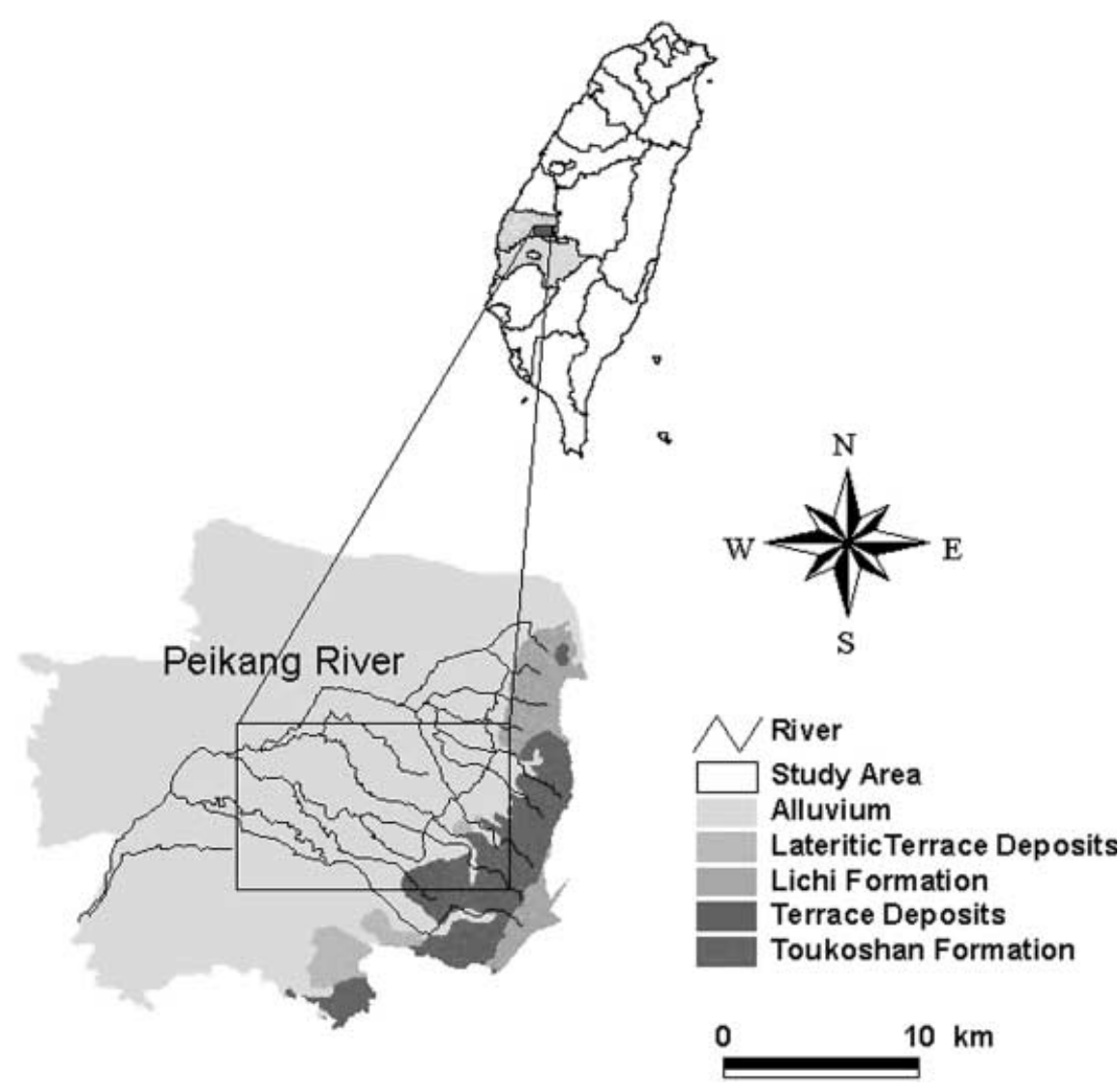

Fig. 1

The locations of the study area
An experimental variogram $\gamma(h)$, is given by:

$$
\gamma(h)=1 /[2 n(h)] \sum_{i=1}^{n(h)}\left[Z\left(x_{i}+h\right)-Z\left(x_{i}\right)\right]^{2}
$$

where $\gamma(h)$ denotes the variogram for interval lag distance class $h$, and $n(h)$ represents the number of pairs separated by the lag distance $h$.

An anisotropic experimental variogram is defined as:

$\gamma(h, \theta)=1 /[2 n(h, \theta)] \sum_{i=1}^{n(h, \theta)}\left[Z\left(x_{i}+h, \theta\right)-Z\left(x_{i}\right)\right]^{2}$

where $\theta$ is the angle along $x_{i}$ to $x_{i}+h$.

Ordinary kriging, as applied within moving data neighborhoods, is a non-stationary algorithm corresponding to a non-stationary random function model with varying mean but stationary covariance (Deutsch and Journel 1992). Kriging estimates are weighted sums of the adjacent sample concentrations. The weights depend on the correlation structure exhibited. For illustration, if data appear highly continuous in space, points closer to the estimates receive higher weights than those farther away. The criterion for selecting these weights is to minimize estimation variance. In this framework, kriging estimates can be regarded as the most accurate linear estimator (i.e., best linear unbiased estimator). At an unsampled location and for a given variogram, a kriging estimate can simply be considered an optimally weighted average of the surrounding sampled data (Cressie 1990). Kriging estimates the value of the random field at an unsampled location $X_{0}$ based on the given measured values in the linear form (Rouhani 1985)

$Z^{\star}\left(X_{0}\right)=\sum^{N} \lambda_{i 0} Z\left(X_{i}\right)$

where $Z^{\star}\left(X_{0}\right)$ denotes kriging estimates at $X_{0}, Z\left(X_{i}\right)$ represents measured values at $X_{i}, i=1, \ldots, N$, and $\lambda_{i 0}$ is kriging weight for $Z\left(X_{i}\right)$ to estimate $Z^{\star}\left(X_{0}\right)$.

\section{Simulation by simulated annealing}

The annealing algorithm requires that the image is perturbed by simulating thermal perturbation (Deutsch and Cockerham 1994). However, simulated annealing is an optimization technique to generate an initial field by drawing random values from a given histogram. Swapping the values in pairs of grid nodes not involving a conditioning datum sequentially modifies this initial field. A swap is accepted if the objective function is lower (Deutsch and Journel 1992). This objective function $(O)$ is defined as an average squared difference between the experimental and given variogram.

$O=\sum_{h} \frac{\left[\gamma^{*}(h)-\gamma(h)\right]^{2}}{\gamma(h)^{2}}$

where $\gamma(h)$ is the pre-specified variogram, and $\gamma^{\star}(h)$ represents the variogram of the simulated realization. 


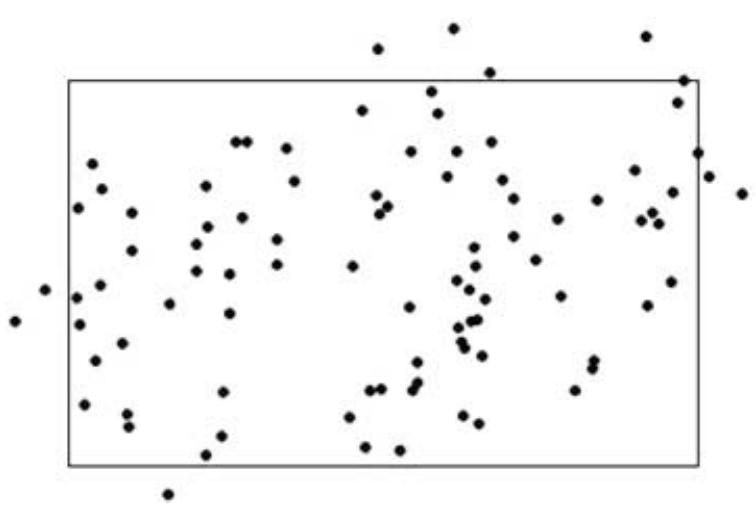

(a)

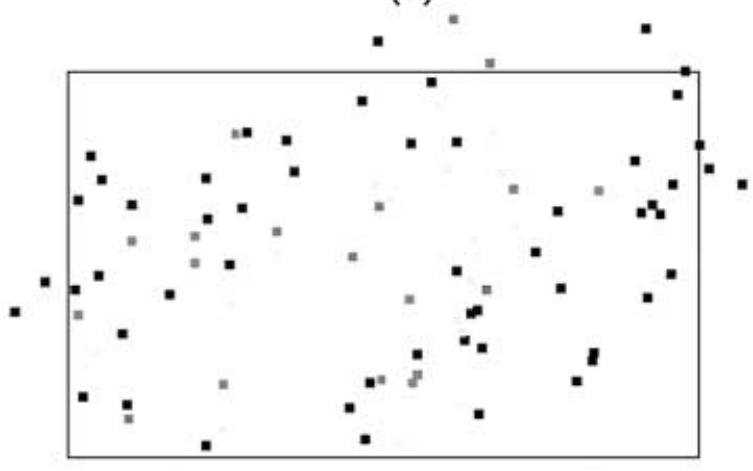

(b)

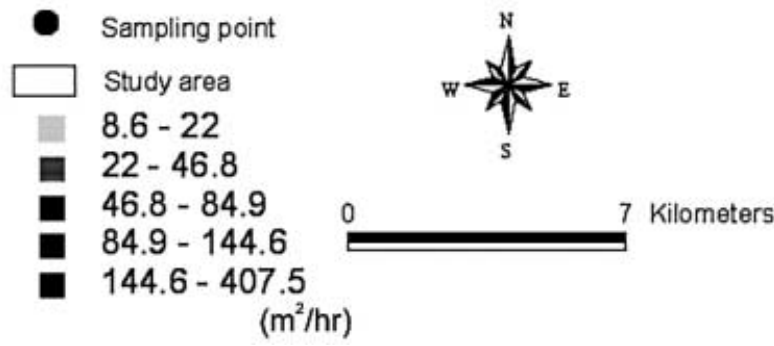

Fig. 2

a The locations of sampling wells in the study area. $\mathbf{b}$ Measured values of transmissivity

A temperature function (the Boltzman distribution) in the simulated annealing procedure controls how the speed at which the optimization function is reduced by allowing certain switches which increase the optimization function (Deutsch and Journel 1992; Eggleston and others 1996). The parameter $t$ of the temperature function is termed the temperature in the annealing procedure. The higher the temperature, the more chance of an unfavorable swap being accepted (Deutsch and Journel 1992).
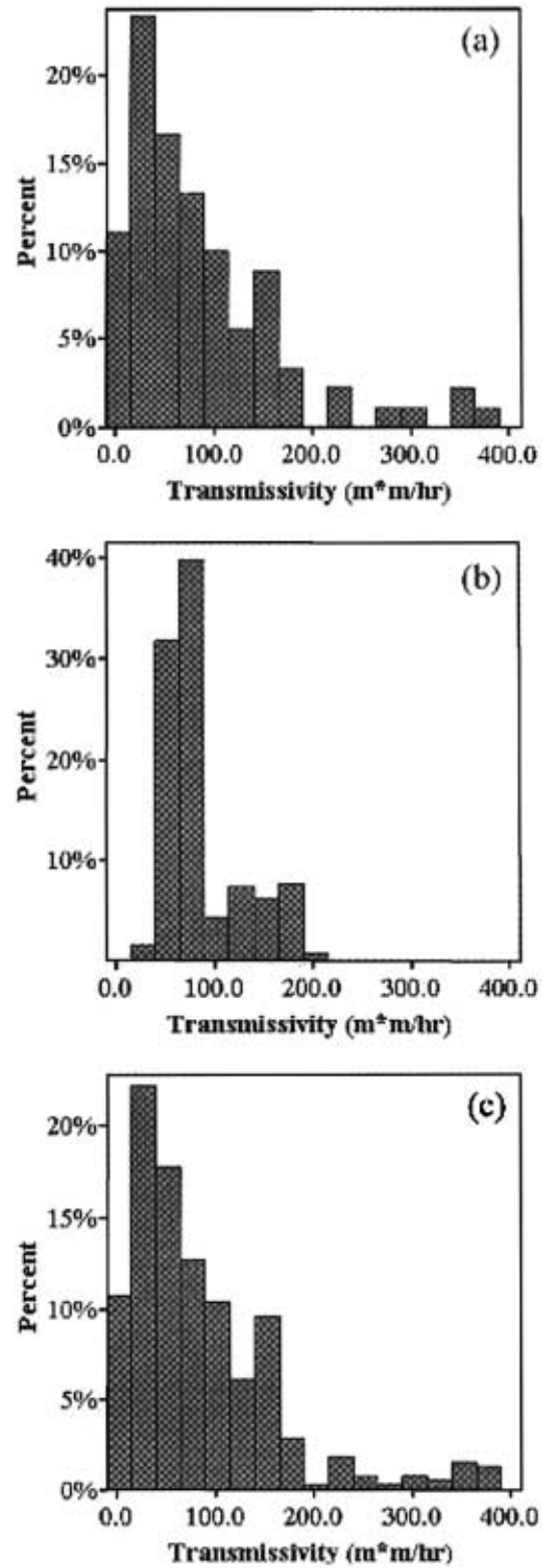

Fig. 3a-c

The histograms of transmissivity of a measured values; $\mathbf{b}$ kriged values; c simulated values (SAS1)

$P\{$ accept $\}= \begin{cases}1, & \text { if } O_{\text {new }} \leq O_{\text {old }} \\ e^{\frac{O_{\text {new }}-O_{\text {old }}}{t}} & \text {, otherwise }\end{cases}$
Table 1

Descriptive statistics of measured transmissivity. $S D$ Standard deviation; $T$ transmissivity; $N$ sampling numbers

\begin{tabular}{|c|c|c|c|c|c|c|c|c|}
\hline & $N$ & $\begin{array}{l}\text { Mean } \\
\left(\mathrm{m}^{2} / \mathrm{h}\right)\end{array}$ & $\begin{array}{l}\text { Median } \\
\left(\mathrm{m}^{2} / \mathrm{h}\right)\end{array}$ & $\begin{array}{l}\operatorname{Min} \\
\left(\mathrm{m}^{2} / \mathrm{h}\right)\end{array}$ & $\begin{array}{l}\operatorname{Max} \\
\left(\mathrm{m}^{2} / \mathrm{h}\right)\end{array}$ & $\begin{array}{l}\mathrm{SD} \\
\left(\mathrm{m}^{2} / \mathrm{h}\right)\end{array}$ & Skewness & Kurtosis \\
\hline $\mathrm{T}$ & 92 & 93.088 & 64.275 & 8.637 & 407.483 & 92.082 & 1.872 & 3.352 \\
\hline
\end{tabular}


In this work the variogram models of transmissivity are also fitted within GS+ (Gamma Design 1995). The source codes of OKB2DM and SASIM in GSLIB (Deutsch and Journel 1992) were modified to perform ordinary kriging and simulated annealing for estimating and simulating transmissivity. These simulations and estimates were performed in a square 38 column by a 28 -row grid comprising 1,664 50×50 m cells. Five simulations of simulated annealing are performed in these 1,664 cells. The results are transferred into Arcview 3.0a (ESRI 1998) to display them and identify the spatial patterns of transmissivity.

\section{Results and discussion}

\section{Spatial correlation structure}

Experimental variograms were calculated for transmissivity at the same active lag and lag interval for isotropic and anisotropic spatial structure analyses. A reasonably consistent set of best-fit models with minimum RSS (model reduced sum of squares) and maximum $\mathrm{r}^{2}$ (regression coefficient) values were generated by least squares model fitting of these variograms. Moreover, in anisotropic structure analyses the principal axis is the base axis, defined as the initial direction for anisotropic structure analyses, from which the offset angles are calculated. Offset angles are at $0,45,90$ and $135^{\circ}$ clockwise from the base axis (Gamma Design 1995). The axis of $0^{\circ}$ is defined in relation to the north-south axis. The points aligned sufficiently closely to one or another of these angles, with a $22.5^{\circ}$ tolerance, are included in the anisotropic analysis of that angle.

Table 2 lists the parameters from representative models, including the spherical, exponential and Gaussian models. A Gaussian model with nugget effect $=5,630\left(\mathrm{~m}^{2} / \mathrm{h}\right)^{2}$, sill $=9,120\left(\mathrm{~m}^{2} / \mathrm{h}\right)^{2}$ and range $=19.09 \mathrm{~km}$ had the best fit among other available models (exponential or spherical) for the values investigated herein. Similarly, for anisotropic variography the experimental variogram of measured transmissivity was calculated for the transmissivity data investigated herein at $0,45,60$ and $90^{\circ}$ with $22.5^{\circ}$ tolerance. The best fit variograms of transmissivity in the above directions are the Gaussian model with nugget effect $=6,160.0\left(\mathrm{~m}^{2} / \mathrm{h}\right)^{2}$, sill=4,760.0 $\left(\mathrm{m}^{2} / \mathrm{h}\right)^{2}$, minimum range $=17.24 \mathrm{~km}$ and maximum range $=17.24 \mathrm{~km}$, as listed in Table 3 . The variogram model with the same minimum and maximum range reveals that the spatial structure of measured transmissivity is isotropic. These variography results also confirm that the measured transmissivity data

Table 2

Variogram model of measured transmissivity. RSS Model reduced sums of square; $r^{2}$ regression coefficient

\begin{tabular}{|c|c|c|c|c|c|}
\hline Model & $\begin{array}{l}\text { Nugget } \\
\left(\mathrm{m}^{2} / \mathrm{h}\right)^{2}\end{array}$ & $\begin{array}{l}\text { Sill } \\
\left(\mathrm{m}^{2} / \mathrm{h}\right)^{2}\end{array}$ & $\begin{array}{l}\text { Range } \\
(\mathrm{km})\end{array}$ & RSS & $r^{2}$ \\
\hline Exponential & 3860.00 & 12790.00 & 12.46 & $2.28 \mathrm{E} 09$ & 0.268 \\
\hline Spherical & 4300.00 & 9610.00 & 20.14 & $2.25 \mathrm{E} 09$ & 0.278 \\
\hline Gaussian & 5630.00 & 9120.00 & 19.09 & $2.21 \mathrm{E} 09$ & 0.290 \\
\hline
\end{tabular}

display an isotropic formation with a high nugget effect. The nugget effect illustrated that some transmissivity data display small-scale variation in the study area.

\section{Statistics concerning estimation and simulation}

The estimations and simulations are based on the above isotropic variogram model and 92 observations of transmissivity. Figures $3 \mathrm{~b}-\mathrm{c}$ and 4 display histograms of estimates and simulations. These histograms illustrate that the simulation method accurately matched the right- and lefthand tails of the distribution for transmissivity, which contain the high and low transmissivity values. Moreover, these figures also show that the shapes of histogram kurtosis of simulated realizations fitted those of the measured transmissivity.

Table 4 lists the statistics relating to kriging estimates and simulations of transmissivity. Simulated annealing reproduce the statistics of transmissivity better than most techniques, including the mean values listed in Tables 1 and 4 . Table 4 shows that annealing simulation can better produce the empirical data relating to measured transmissivity.

The simulated median values are almost similar to those of the measured data, as listed in Tables 1 and 4 . The simulation results also indicate that the 25th percentiles of the transmissivity simulations are identical to those of the measured data, as listed in Tables 1 and 4. Meanwhile, the 25 th and 75th percentiles of the simulations are identical to those of the measured data, as listed in Tables 1 and 4 . The mean values of ordinary kriging estimated values in the investigation area closely approach the mean of the empirical values of transmissivity. The median, variance, kurtosis, and skewness of the simulations closely approximate the investigated transmissivity data, as displayed in Tables 1 and 4 . The above results indicate that the ordinary kriging process may not preserve the variability and skewness of the investigated process. Moreover, minimizing the variation in prediction error involves smoothing the actual variability. Simulated annealing can reproduce the statistics of empirical data. However, simulated annealing reproduces the distribution of the investigated transmissivity more accurately. These figures also indicate that kriging produces smoothed data which cannot capture the spatial variability of the measured transmissivity data in the study area.

\section{Correlation of estimation and simulation}

In the correlation analysis, both the Pearson and Spearman correlation coefficients were calculated for

Table 3

Anisotropic variogram models of measured transmissivity. RSS Model reduced sums of square; $r^{2}$ regression coefficient

\begin{tabular}{|c|c|c|c|c|c|c|}
\hline Model & $\begin{array}{l}\text { Nugget } \\
\text { effect } \\
\left(\mathrm{m}^{2} / \mathrm{h}\right)^{2}\end{array}$ & $\begin{array}{l}\text { Sill } \\
\left(\mathrm{m}^{2} / \mathrm{h}\right)^{2}\end{array}$ & $\begin{array}{l}\text { Max. } \\
\text { range } \\
(\mathrm{km})\end{array}$ & $\begin{array}{l}\text { Min. } \\
\text { range } \\
(\mathrm{km})\end{array}$ & RSS & $\mathrm{r}^{2}$ \\
\hline & 4970.00 & 652000 & 9.3 & 9.39 & $8.50 \mathrm{E} 8$ & .18 \\
\hline & 5490.0 & 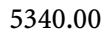 & 20. & 20. & 88 & 199 \\
\hline Gaussian & 6160.00 & 4760.00 & 17.24 & 17.24 & $8.76 \mathrm{E} 8$ & 0.208 \\
\hline
\end{tabular}



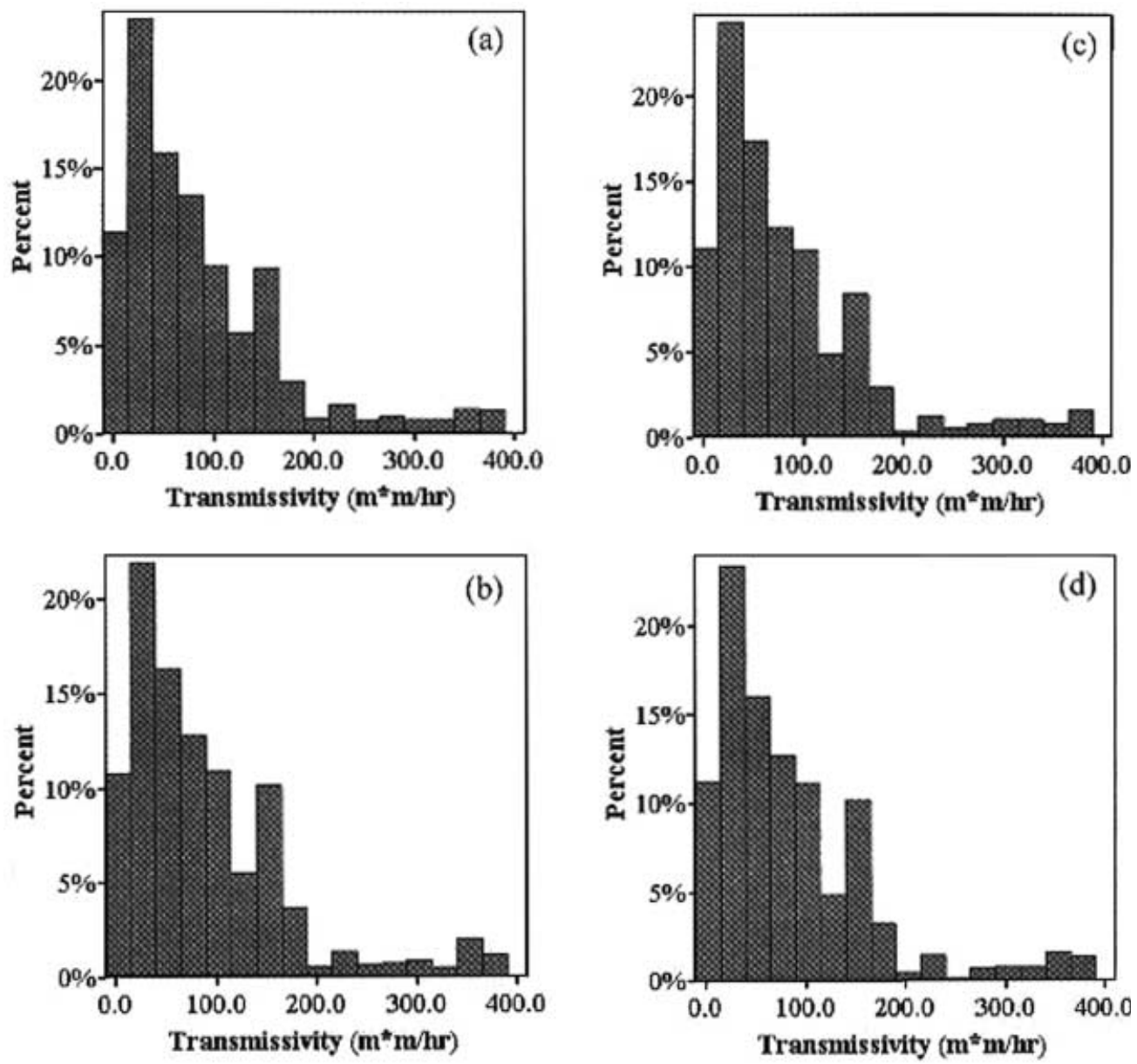

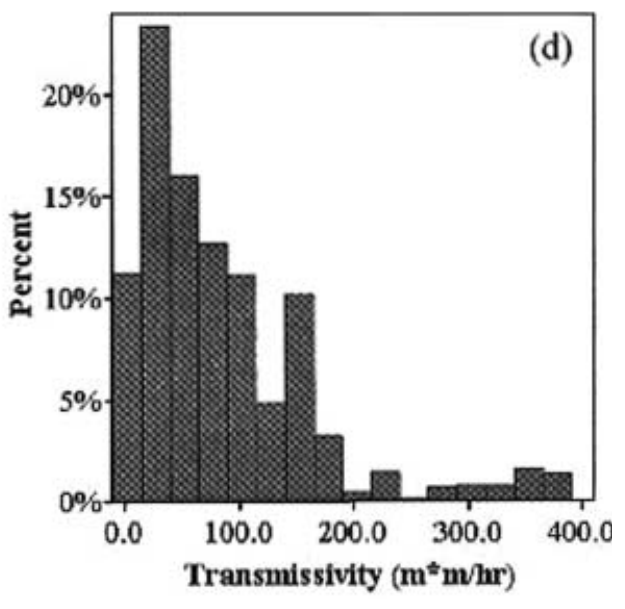

Fig. 4a-d

The histograms of simulated transmissivity of a SAS2; b SAS3; c SAS4; d SAS5
Table 4

Descriptive statistics of kriging estimates and simulations. $O K$ Ordinary kriging; $S A S$ simulated annealing simulation; $S D$ standard deviation

\begin{tabular}{|c|c|c|c|c|c|c|}
\hline & OK & SAS1 & SAS2 & SAS3 & SAS4 & SAS5 \\
\hline$N$ & 1,664 & 1,664 & 1,664 & 1,664 & 1,664 & 1,664 \\
\hline Mean & 87.066 & 90.433 & 93.587 & 94.880 & 90.290 & 91.251 \\
\hline Median & 73.366 & 64.749 & 65.583 & 70.000 & 62.265 & 65.593 \\
\hline SD & 39.848 & 85.074 & 91.010 & 90.093 & 89.262 & 87.826 \\
\hline Skewness & 1.211 & 1.866 & 1.803 & 1.771 & 1.900 & 1.868 \\
\hline Kurtosis & 0.330 & 3.577 & 3.027 & 2.963 & 3.427 & 3.423 \\
\hline Min. & 33.783 & 8.637 & 8.637 & 8.637 & 8.637 & 8.637 \\
\hline Max. & 196.713 & 407.483 & 407.483 & 407.483 & 407.483 & 407.483 \\
\hline 25 th percentile & 59.564 & 34.491 & 31.171 & 33.915 & 30.611 & 33.250 \\
\hline 75th percentile & 103.336 & 123.387 & 128.368 & 129.547 & 116.554 & 120.063 \\
\hline
\end{tabular}

1,664 pairs, to identify the interrelationships of estimation and simulation, especially realizing simulations, as listed in Tables 5 and 6.

Table 5 lists Pearson correlation coefficients among estimated results and simulated realizations. The range of correlation coefficients between kriging estimates and each realization varies from 0.577 to 0.787 , and exhibits a strong linear correlation, as illustrated in Table 5. These results imply that the kriging estimates and simulated realizations have a common origin and exhibit a similar spatial pattern of transmissivity in the study area. Moreover, the correlation coefficients among the realizations are strongly significant at the 0.01 probability level according to the 2 -tailed test, as presented in Table 5. The range of these coefficients is from 0.602 to 0.842 .
Table 6 lists Spearman correlation coefficients among estimates and simulations. The correlation between estimates and each simulation shows a significant coefficient $(0.719-0.884)$ at the 0.01 level. The correlation coefficients (0.713-0.913) of estimates and simulations are extremely significant at the 0.01 level. Meanwhile, the nonparametric correlation results indicate that simulation realizations exhibit similar spatial patterns to each other.

To assess the results of estimation and simulation on the eastern section of the Peikang River, 1,624 cells were selected from estimated and simulated maps of transmissivity using Arcview 3.0a. Table 7 displays the Pearson correlation coefficients among estimated results and simulated realizations at these 1,624 cells. The range of correlation coefficients between kriging estimates and each 
realization is from 0.595 to 0.787 , and displays a strong linear correlation, as shown in Table 7. These results confirm that the kriging estimates and simulated realizations have a common origin and exhibit a similar spatial pattern of transmissivity in the eastern part of the Peikang River. Moreover, the correlation coefficients among the realizations are extremely significant at the 0.01 probability level according to the 2-tailed test, as presented in Table 7. These coefficients range from 0.614 to 0.895 . Table 8 lists Spearman correlation coefficients among estimates and simulations for these 1,624 cells. According to this table, the correlation between kriging estimates and each simulation reveals a significant coefficient $(0.726-$ $0.885)$ at the 0.01 level. The correlation coefficients $(0.726-$ 0.945 ) among simulations are strongly significant at the 0.01 level. These nonparametric correlation results demonstrate that realizations of simulations on the eastern part of Peikang River exhibit similar spatial patterns. Moreover, these results also indicated that the realizations of simulated annealing simulation consistently present the spatial distribution of transmissivity on the east bank of the Peikang River.

\section{Spatial patterns of transmissivity}

Ordinary kriging and simulated annealing simulation for transmissivity in this study area are also performed and mapped in a geographic information system. The kriging estimated and conditional simulated transmissivity maps illustrate that the low values formed an approximately triangular shape in the center of this study area (Figs. 5 and 6). The maps also show that the transmissivity values gradually increased from this triangularly shaped area to the surrounding area of this center area, as illustrated in Figs. 5 and 6. Moreover, the high transmissivity values were located on the Dulliu Hill in the east part of the study area and on the west of the Peikang River in the northwestern part of the study area, as illustrated in Figs. 5 and 6. Moreover, the transmissivity values of the study area gradually decreased from the Dulliu Hill to the center of the area. However, these simulated transmissivity maps fully display the characteristics of the geological formation of this study area (Figs. 1, 5 and 6). These maps also confirm that the study area has a rather typical alluvia fan stratum structure, since the gravel layer on the east side is thick, gradually thinning towards the west and southwest,
Table 5

Pearson correlation coefficient of estimation and simulation. ** Correlation is significant at the 0.01 level (two-tailed test); $O K$ ordinary kriging; SAS simulated annealing simulation

\begin{tabular}{|c|c|c|c|c|c|c|}
\hline & OK & SAS1 & SAS2 & SAS3 & SAS4 & SAS5 \\
\hline OK & 1.000 & $0.773^{* *}$ & $0.577^{\star *}$ & $0.656^{* *}$ & $0.787^{* *}$ & $0.685^{* *}$ \\
\hline SAS1 & $0.773^{\star *}$ & 1.000 & $0.602^{\star *}$ & $0.712^{\star *}$ & $0.842^{* *}$ & $0.739^{* *}$ \\
\hline SAS2 & $0.577^{\star *}$ & $0.602^{* *}$ & 1.000 & $0.611^{* *}$ & $0.649^{* *}$ & $0.688^{* *}$ \\
\hline SAS3 & $0.656^{* *}$ & $0.712^{* *}$ & $0.611^{* *}$ & 1.000 & $0.629 * *$ & $0.624^{* *}$ \\
\hline SAS4 & $0.787^{\star *}$ & $0.842^{* *}$ & $0.649^{* *}$ & $0.629^{* *}$ & 1.000 & $0.811^{* *}$ \\
\hline SAS5 & $0.685^{\star *}$ & $0.739 * *$ & $0.688^{* *}$ & $0.624^{* *}$ & $0.811^{\star *}$ & 1.000 \\
\hline
\end{tabular}

Table 6

Spearman correlation coefficient of estimation and simulation. ** Correlation is significant at the 0.01 level (two-tailed); $O K$ ordinary kriging; $S A S$ simulated annealing simulation

Table 7

Pearson correlation coefficient of estimation and simulation. ** Correlation is significant at the 0.01 level (two-tailed); $O K$ ordinary kriging; $S A S$ simulated annealing simulation

Table 8

Spearman correlation coefficient of estimation and simulation. ${ }^{* *}$ Correlation is significant at the 0.01 level (two-tailed); $O K$ ordinary kriging; $S A S$ simulated annealing simulation

\begin{tabular}{|c|c|c|c|c|c|c|}
\hline & $\mathrm{OK}$ & SAS1 & SAS2 & SAS3 & SAS4 & SAS5 \\
\hline $\mathrm{OK}$ & 1.000 & $0.884^{* *}$ & $0.719^{* *}$ & $0.813^{* *}$ & $0.860^{* *}$ & $0.813^{\star *}$ \\
\hline SAS1 & $0.884^{* *}$ & 1.000 & $0.832^{\star *}$ & $0.913^{\star *}$ & $0.942^{* *}$ & $0.898^{\star *}$ \\
\hline SAS2 & $0.719^{\star *}$ & $0.832^{\star *}$ & 1.000 & $0.905^{\star *}$ & $0.713^{* *}$ & $0.844^{\star *}$ \\
\hline SAS3 & $0.813^{\star *}$ & $0.913^{* *}$ & $0.905^{* *}$ & 1.000 & $0.803^{* *}$ & $0.855^{\star *}$ \\
\hline SAS4 & $0.860^{* *}$ & $0.942^{* *}$ & $0.713^{* *}$ & $0.803^{\star *}$ & 1.000 & $0.901^{\star *}$ \\
\hline SAS5 & $0.813^{\star *}$ & $0.898^{\star *}$ & $0.844^{* *}$ & $0.855^{\star *}$ & $0.901^{* *}$ & 1.000 \\
\hline
\end{tabular}

\begin{tabular}{|c|c|c|c|c|c|c|}
\hline & OK & SAS1 & SAS2 & SAS3 & SAS4 & SAS5 \\
\hline $\mathrm{OK}$ & 1.000 & $0.777^{\star \star *}$ & $0.595^{\star \star}$ & $0.672^{\star *}$ & $0.787^{\star *}$ & $0.765^{\star *}$ \\
\hline SAS1 & $0.777^{\star *}$ & 1.000 & $0.614^{* *}$ & $0.715^{\star *}$ & $0.845^{* *}$ & $0.781^{* *}$ \\
\hline SAS2 & $0.595^{\star *}$ & $0.614^{\star *}$ & 1.000 & $0.623^{* *}$ & $0.671^{\star *}$ & $0.725^{\star *}$ \\
\hline SAS3 & $0.672^{\star *}$ & $0.715^{\star *}$ & $0.623^{\star *}$ & 1.000 & $0.642^{\star *}$ & $0.622^{\star *}$ \\
\hline SAS4 & $0.787^{\star *}$ & $0.845^{\star *}$ & $0.671^{\star *}$ & $0.642^{\star *}$ & 1.000 & $0.895^{\star *}$ \\
\hline SAS5 & $0.765^{\star *}$ & $0.781^{\star *}$ & $0.725^{\star *}$ & $0.622^{* *}$ & $0.895^{\star *}$ & 1.000 \\
\hline
\end{tabular}




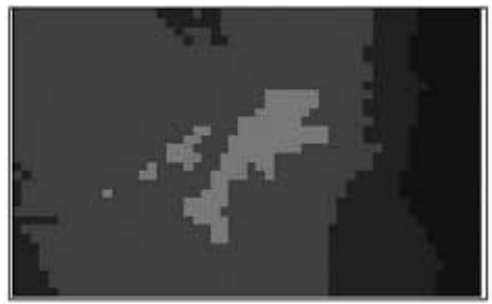

(a)

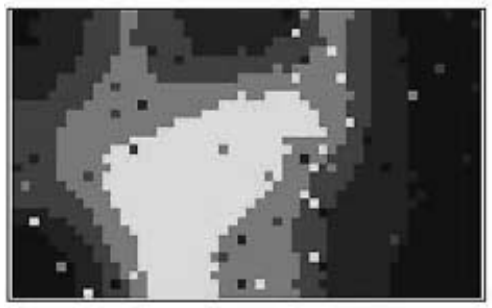

(b)

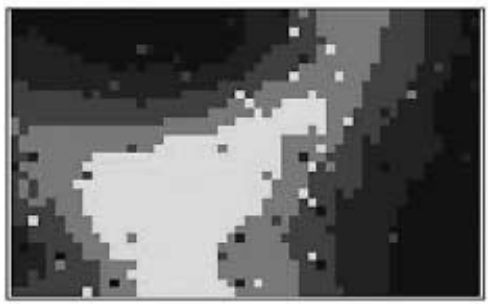

(c)

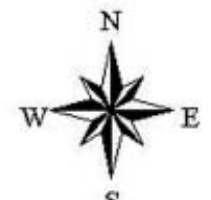

$\mathrm{S}$

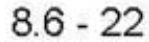

$22-46.8$

$46.8-84.9$

$84.9-144.6$

- $144.6-407.5$

$\left(\mathrm{m}^{2} / \mathrm{hr}\right)$

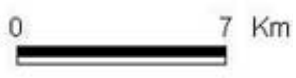

Fig. 5a-c

The spatial maps of transmissivity of a kriged values; $\mathbf{b}$ simulated values (SAS1); c simulated values (SAS2)

whereas the thickness of the muddy and sandy stratum increases correspondingly.

The maps in Figs. 5 and 6) illustrate that the spatial continuity and discontinuity patterns produced by simulated annealing simulation visually resemble those in the map of the investigated transmissivity data. Comparison of Figs. 5 and 6) shows that the kriging results may overestimate the size of the low transmissivity area located in the center of the study area, and underestimate the size of extremely high transmissivity areas located in the east of this study area. These maps also illustrate that kriging estimates are much smoother than in any of the simulations. Comparing the estimated and simulated transmissivity maps, the map made by ordinary kriging estimates shows that kriging tends to smooth out extreme values in the investigated data set, as presented in Figs. 5 and 6). Meanwhile, kriging provides the optimal estimate of transmissivity at unsampled sites, but does not reproduce the spatial variability of the investigated transmissivity data in this case study. Simulated annealing simulation can reproduce the spatial variation of the investigated transmissivity data. Moreover, each simulation realization provides a measure of spatial uncertainty throughout the study area. Meanwhile, the spatial pattern of kriging-estimated results could also be used to enhance the spatial patterns of simulated transmissivity. The simulation realizations illustrated that

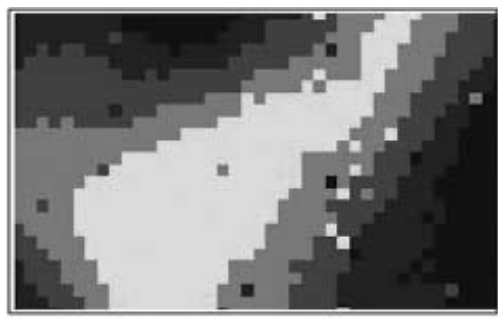

(a)

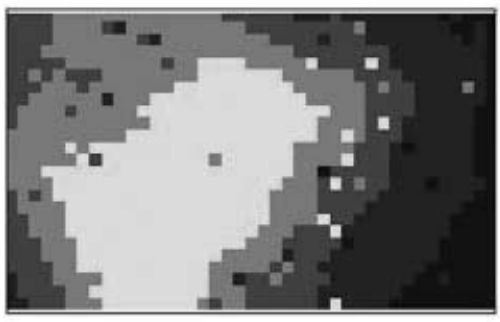

(b)

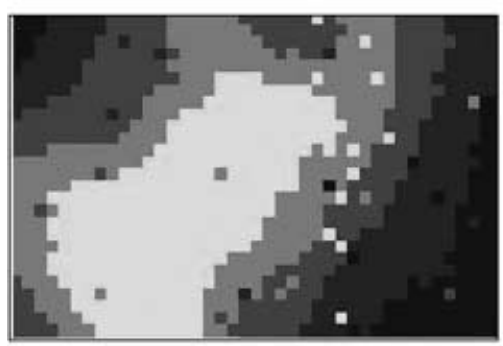

(c)

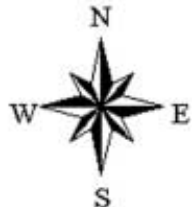

$8.6-22$

$22-46.8$

$46.8-84.9$

$84.9-144.6$

$144.6-407.5$

$\left(\mathrm{m}^{2} / \mathrm{hr}\right)$

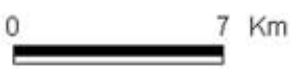

Fig. 6a-c

The spatial maps of transmissivity of a simulated values (SAS3); b simulated values (SAS4); c simulated values (SAS5)

the north, northeast and southeast parts may require additional wells to understand the uncertainty of transmissivity in the study area.

\section{Conclusion}

This study has demonstrated the spatial variability and patterns in measured transmissivity data within the area of interest. Although kriging and simulated annealing can both be used to identify the spatial variability and patterns, ordinary kriging failed to reproduce transmissivity statistics any better than simulation techniques. Meanwhile, besides reproducing the spatial variation of the measured transmissivity, simulated annealing identified global spatial continuity patterns. Compared to global statistics and spatial patterns of transmissivity measurements, the simulated annealing method achieved more accurate results than kriging. Realizations of simulated annealing simulation were consistent in presenting the spatial patterns and uncertainty of transmissivity in the study area. The simulated transmissivity maps fully display the characteristics of the geological formation and tendencies in the study area. The kriging estimated and 
simulated results were also effective in assessing uncertainty and adding additional samples for transmissivity.

\section{References}

Andersson J, Shapiro AM (1983) Stochastic analysis of one-dimensional steady state unsaturated flow: a comparison of Monte Carlo and perturbation methods. Water Resour Res 19(1):121133

Bakr AA, Gelhar LW, Gutjahr AL, Macmillan JR (1978) Stochastic analysis of spatial variability in subsurface flows. 1. Comparison of one- and three-dimensional flows. Water Resour Res 14(2):263-271

Bjerg PL, Hinsby K, Christensen TH, Gravesen P (1992) Spatial variability of hydraulic of an unconfined sandy aquifer determined by a mini slug test. J Hydrol 136:107-122

Capilla JE, Rodrigo J, Gomez-Hernandez JJ (1998) Worth of secondary data compared to piezometric data for the probabilistic assessment of radionuclide migration. Stoch Hydrol Hydraul 12:191-204

Chirlin GR, Dagan G (1980) Theoretical head variogram for steady flow in statistically homogeneous aquifers. Water Resour Res 16(6):1001-1015

Christako G (1992) Random field models in earth sciences. Academic Press, New York

Christensen S (1997) On the strategy of estimating regional-scale transmissivity fields. Ground Water 35(1):131-139

Clifton PM, Neuman SP (1982) Effects of kriging and inverse modeling on conditional simulation of the Avra Valley aquifer in Southern Arizona. Water Resour Res 18(4):1251-1234

Cressie C (1990) The origins of kriging. Math Geol 22(2):239-252

Delhomme JP (1979) Spatial variability and uncertainty in groundwater flow parameters: a geostatistical approach. Water Resour Res 15(2):269-280

Deutsch CV, Cockerham PW (1994) Practical considerations in the application of simulated annealing of stochastic simulation. Math Geol 26(1):67-82

Deutsh C, Journel AG (1992) GSLIB. Geostatistical software library and user's guide. Oxford University Press, New York

Di Federico V, Neuman SP (1997) Scaling of random-fields by means of truncated power variograms and associated spectra. Water Resour Res 33(5):1075-1085

Eggleston JR, Rjostaczer SA, Peirce JJ (1996) Identification of hydraulic conductivity structure in sand and gravel aquifers: Cape Cod data set. Water Resour Res 32(5):1209-1222

ESRI (1998) Arcview 3.0. Environmental Systems Research Institute, Redlands, CA

Fabbri P (1996) Transmissivity in the geothermal Euganean basin: a geostatistical analysis. Ground Water 35(5):881-887
Freeze RA (1975) A stochastic-conceptual analysis of one-dimension groundwater flow in nonuniform homogeneous media. Water Resour Res 11(5):725-741

Gamma Design (1995) GS+: Geostatistics for the environmental sciences. Version 2.3. Gamma Design Software, Plainwell, MI

Hoeksema RJ, Kitanidis PK (1985) Analysis of spatial structure of properties of selected aquifers. Water Resour Res 21(4):563-572

Journel AG, Huijbregts CJ (1978) Mining geostatistics. Academic Press, San Diego

Kentwell DJ, Bloom LM, Comber GA (1999) Improvements in grade tonnage curve prediction via sequential Gaussian fractal simulation. Math Geol 31(3):311-325

Lin YP, Chang TK (2000a) Geostatistical estimation and simulation of the spatial variability of soil zinc. J Environ Sci Health A35(3):327-347

Lin YP, Chang TK (2000b) Simulated annealing and kriging method for identifying the spatial patterns and variability of soil heavy metal. J Environ Sci Health A35(7):1089-1115

Lin YP, Lee CC, Tan YC (2000) Geostatistical approach for identification of transmissivity structure at Duliu area in Taiwan. Environ Geol 40(1-2):111-120

Mowrer HT (1997) Propagating uncertainty through spatial estimation processes for old-growth subalpine forests using sequential Gaussian simulation in GIS. Ecol Model 98:73-86

Neuman SP, Winter CL, Newman CM (1987) Stochastic theory of field-scale Fickian dispersion in anisotropic porous media. Water Resour Res 23(3):453-466

Roth C (1998) Is lognormal kriging suitable for local estimation? Math Geol 30(8):999-1009

Rouhani S (1985) Variance reduction analysis. Water Resour Res 21(6):837-864

Rubin Y (1990) Stochastic modeling of microdispersion in heterogeneous porous media. Water Resour Res 26(1):133-141

Salandin P, Fiorotto V (1998) Solute transport in highly heterogeneous aquifers. Water Resour Res 34(5):949-961

Smith L (1981) Spatial variability of flow parameters in a stratified sand. Math Geol 13(1):1-21

Smith L, Freeze RA (1979) Stochastic analysis of steady state groundwater flow in a bounded domain. 1. One-dimensional simulations. Water Resour Res 15(3):521-528

Sterk G, Stein A (1997) Mapping wind-blown mass transport by modeling variability in space and time. Soil Sci Soc Am J 61:232-239

Tsao ES (1982) The study of groundwater mathematical model in Yu-Ling County. Agricultural Engineering Center, Tau-Yuan, Taiwan

Varljen MD, Shafer JM (1991) Assessment of uncertainty in time related captures zones using conditional simulation of hydraulic conductivity. Ground Water 29:737-748

Wang XJ, Zhang ZP (1999) A comparison of conditional simulation, kriging and trend surface analysis for soil heavy metal pollution pattern analysis J Environ Sci Health A34(1):73-89 